\title{
EL DERECHO DE ACCESO A LA INFORMACIÓN PÚBLICA EN ESPAÑA Y LOS PAÍSES BAJOS. DOS ESCENARIOS MEJORABLES
}

\author{
Manuel Sánchez de Diego Fernández de la Riva y \\ Laura Tejedor Fuentes
}

doi: 10.18543/ed-64(2)-2016pp305-343

\begin{abstract}
SUMARIO. 1. InTRODUCCIÓN. 1.1. El convenio de Tromsø, un marco ideal no ratificado. 1.2. Open Government Partnership. 2. Historia. EL INTENTO DE CREAR UN DERECHO FUNDAMENTAL. 2.1. España. Fuera de los derechos fundamentals. 2.2. Países Bajos. Principio de Gobierno Abierto desde 1983 pero fuera de los derechos fundamentales. 3. DOCTRINA SOBRE TRANSPARENCIA. 3.1. España. Un exceso de normas. 3.2. El escenario holandés. Una sola norma. 4. INFORMACIÓN PROACTIVA Y REUTILIZACIÓN. 4.1. España. Esfuerzo del Portal de Transparencia con reutilización deficient. 4.2. Holanda. La reutilización se cobra. 5. Sujetos obligados. 5.1.España. Amplio ámbito de aplicación pero en desiguales niveles. 5.2. Holanda. Sólo el poder ejecutivo. 6. Solicitud de ACCESO Y TRAMitación. 6.1. España. Complicado proceso informático con un mes de respuesta. 6.2. Holanda. Proceso por correo postal con un matiz que hace la diferencia. 7. LímITES, CAUSAS DE INADMISIÓN Y PROTECCIÓN DE DATOS. 7.1. España. Límites confuses. 7.2. Holanda. Positiva valoración del interés público. 8. ÓRgANO DE CONTROL. 8.1. España. Órgano de control dependiente. 8.2 Holanda. Sin órgano de control. 9. El ACCESO REAL A LOS DATOS. 9.1. España. Amplias excepciones. 9.2. Holanda. Acceso complicado y no reutilizable. 10. CONCLUSIONES. 11. BIBLIOGRAFÍA.
\end{abstract}




\section{INTRODUCCIÓN}

Este trabajo tiene por objeto el estudio de los marcos jurídicos de acceso a la información pública en España y Holanda ${ }^{1}$. Dicho acceso a la información pública y la transparencia en su concepción actual se remonta al siglo XVIII en Suecia, aunque a nivel internacional es en los últimos años cuando se ha desarrollado en la gran mayoría de los países occidentales.

Se emplea una metodología inductiva, a partir de la recopilación y estudio de los textos constitucionales y legales de ambos países, desde la que se desarrollan unas conclusiones de tipo cualitativo sobre cuestiones esenciales en la transparencia pública.

La elección de Los Países Bajos se justifica en el sentido de escoger un país de la Unión Europea que, por un lado tenga una trayectoria general de transparencia, unido al hecho que uno de los firmantes ha tenido la oportunidad de realizar una estancia de investigación en la Universidad de Leiden ${ }^{2}$. La peculiar tradición normativa holandesa combina unas reglas proactivas de transparencia con la confianza en el autocontrol de la clase política y coloca a este modelo como un elemento de comparación muy interesante para España, al ofrecer un modelo de contraste bastante diferente respecto al proporcionado por los países anglosajones. Apreciamos un cierto paralelismo entre la situación de ambos países y, por otro lado, unas cuestiones divergentes que serán objeto de nuestro análisis.

Existe un elemento común de los países occidentales en el desarrollo del derecho de acceso a la información pública y, por tanto, de la transparencia del sector público y los sujetos asimilados y, precisamente se encuentra en los requerimientos que se encuentran a nivel internacional. Entre ellos podemos citar el Convenio 205 del Consejo de Europa sobre el Acceso a Documentos Públicos, firmado en Tromsø (2009), o la Alianza para el Gobierno Abierto (Open Government Partnership, en adelante OGP).

\subsection{El convenio de Tromsø, un marco ideal no ratificado}

El Convenio del Consejo de Europa sobre el Acceso a Documentos Públicos es considerado por los especialistas en acceso a la información y transparencia, entre ellos Marga (Groothuis 2014, 87), profesora de la Facultad de Derecho de la Universidad de Leiden, como el último escalón y un modelo a

${ }^{1}$ La denominación de Países Bajos se refiere al país completo, mientras que el nombre Holanda se emplea para las dos provincias centrales. Sin embargo, puesto que el nombre más usado a nivel internacional es Holanda, en este artículo se usa indistintamente la denominación de Países Bajos u Holanda para denominar al país en su conjunto.

${ }^{2}$ Laura Tejedor Fuentes entre septiembre y diciembre de 2013. 
imitar. Sin embargo, y como detallaremos más abajo, aún no ha sido ratificado por Holanda, ni por España.

El Convenio apuesta por la publicidad activa o proactiva, cuando dice en su artículo 10 que «por su iniciativa propia y cuando sea conveniente, las autoridades públicas tomarán las medidas necesarias para poner a disposición de todos los documentos públicos en su poder para promover la transparencia y la eficacia de la administración y para fomentar la participación informada del público en materias del interés general».

La publicidad proactiva o activa se entiende como la puesta a disposición de los ciudadanos de información sin que medie una petición previa; frente a la publicidad reactiva, que exige una petición de información a un sujeto obligado a la transparencia para que éste responda. Del mismo modo, se diferencia entre transparencia proactiva y reactiva (Access Info 2010).

El Convenio establece un amplio ámbito subjetivo de aplicación, cuando recoge en su artículo 1.2 que los sujetos obligados a proporcionar información son todas las autoridades públicas, tanto el gobierno y administración a nivel nacional, regional y local; los organismos legislativos y autoridades judiciales, así como las personas naturales o jurídicas cuando ejercen como autoridad administrativa o manejan fondos públicos.

En relación al ámbito objetivo, el Convenio califica de forma muy abierta y satisfactoria, el objeto de la solicitud como «toda la información registrada [archivada] de cualquier forma, elaborada o recibida, y en posesión de las autoridades públicas», lo cual amplia de forma considerable el mero registro administrativo o el documento público.

El Convenio determina claramente en su artículo 4.1 que los solicitantes de información $n .^{\circ}$ deberán ser obligados a dar las razones por las que quieren la información solicitada, lo cual supone un paso más a favor del derecho de acceso.

También proclama el principio de publicidad de todos los documentos públicos y fija en su artículo tercero una serie limitada de excepciones al derecho de acceso a la información pública. Entre ellos la seguridad nacional, la defensa y las relaciones internacionales; la seguridad pública; la prevención, la investigación y el procesamiento de actividades criminales, las investigaciones disciplinarias; la inspección, control y supervisión por autoridades públicas, la intimidad y otros intereses privados legítimos o los intereses económicos y comerciales.

Para que estas excepciones sean admisibles deben cumplir tres requisitos: estar definidas por ley, ser necesarias en una sociedad democrática y tener como objeto la protección de alguno de los límites citados en el Convenio. Además, continuando en el artículo 3: «el acceso a la información contenida en un documento oficial puede ser rechazado si puede o probablemente pueda dañar los intereses mencionados, a menos que haya un interés público 
que prevalezca en dicha revelación». Esto último es conocido como el test de interés público, que supone la valoración de la divulgación de la información respecto del interés atendido con su denegación. De alguna forma permite superar cualquier límite cuando existe un interés público superior en la revelación de la información. Esto no quiere decir que una solicitud de información se someta a un juicio de interés público, sino que ante una solicitud de información pública que pueda ser rechazada por algún límite admisible, la información debe ser entregada si existe un interés público. Podemos referirnos a que el interés público concurre con el interés privado del peticionario para lograr que se entregue la información solicitada.

En el Convenio del Consejo de Europa no se fija un plazo concreto de resolución al acceso, sólo establece en su artículo 5.4 que deberán limitarse a lo esencial para poder resolver la petición y que «la decisión deberá ser resuelta, comunicada y ejecutada tan pronto como sea posible o dentro de un límite de tiempo razonable que ha sido especificado de antemano. «En Derecho comparado los plazos son muy variados, si bien oscilan entre los siete días hábiles (Perú), pasando por diez días (Portugal, Argentina), quince días (Finlandia, Polonia, República Checa), veinte días (México, Reino Unido, Eslovenia, Chile), hasta un mes (Francia e Italia)» (Fernández Ramos y Pérez Monguió 2014). En cualquier caso, la media de entrega de la información en Europa se fija en quince días. Por su parte, el plazo para resolver las solicitudes de información pública también es diferente en algunas de las Comunidades Autónomas de España (INAP 2016, 91-95)

En el último punto de este mismo artículo se establece que los funcionarios deberán ayudar a los solicitantes de información y viene a exigir que cuando la autoridad pública «rechaza el acceso total o parcial a un documento oficial deberá dar las razones de la denegación». Asimismo, «el solicitante tiene el derecho a recibir sobre su petición una justificación escrita de la denegación de esa autoridad pública». Además el artículo ocho regula el derecho del ciudadano a un procedimiento de revisión rápido y gratuito de aquellas peticiones de documentos oficiales que le hayan sido denegadas expresa o implícitamente ante un órgano independiente y ante los tribunales de justicia.

El Convenio también prohíbe la discriminación, pues establece en su artículo segundo que «cada parte [Estado] garantizará el derecho de cualquiera, sin discriminación de ningún tipo, a acceder, bajo petición, a los documentos públicos en posesión de las autoridades públicas». Manifestación que contrasta con la realidad discriminatoria ${ }^{3}$.

${ }^{3}$ Aunque realizada en el año 2004, la encuesta sobre leyes y prácticas del acceso a la información en catorce países reveló la discriminación que sufren los "excluded group» (minorías excluidas) para acceder a la información pública frente a los resultados obtenidos por periodistas, empresarios, representantes de ONG's o solicitantes sin afiliación 
En lo referente al coste de la información, el Convenio establece en su artículo 7.1 que la consulta de documentos debe ser siempre gratuita y que sólo se podrá cobrar gastos por copias y la entrega de información, pero que éstos no deben superar el coste real.

El Convenio aún no ha entrado en vigor pues no se han conseguido las diez ratificaciones necesarias. En octubre de 2016 solo lo habían ratificado nueve países que, enumerados en orden cronológico son (Council 2016): Noruega, en septiembre de 2009; Hungría, en enero de 2010; Suecia, en abril de 2010; Montenegro, en enero de 2012; Bosnia Herzegovina, en enero de 2012; Lituania, en julio de 2012; Finlandia, en febrero de 2015; Estonia, en enero de 2016 y Moldavia, en septiembre de 2016. Ni España ni los Países Bajos han ratificado aún dicho Convenio.

\subsection{Open Government Partnership}

La OGP «busca que, de manera sostenida, los gobiernos sean más transparentes, rindan cuentas y mejoren la capacidad de respuesta hacia sus ciudadanos - con el objetivo final de mejorar la calidad del gobierno, así como la calidad de los servicios que reciben los ciudadanos. Esto requiere un cambio de normas y cultura para garantizar un diálogo y colaboración genuinos entre gobierno y sociedad civil» (OGP 2015a). Se inició en 2011 con el compromiso de ocho países, los fundadores y, en la actualidad cuenta con 64 países comprometidos. En todos esos países, gobierno y sociedad civil trabajan juntos para desarrollar e implementar reformas ambiciosas en torno al concepto de gobierno abierto.

Los países participantes en la OGP se organizan en grupos basados en su fecha de incorporación a la Alianza. Después de incorporarse, los países están obligados a seguir el cronograma de su grupo para implementar un plan de acción, evaluar sus propios avances, apoyar un informe independiente y desarrollar nuevos planes de acción.

Los ocho países fundadores formaron el grupo uno (Brasil, Indonesia, México, Noruega, Filipinas, Sudáfrica, Reino Unido y Estados Unidos) al incorporarse a OGP en septiembre de 2011; los 39 países que se incorporaron en abril de 2012 conforman el grupo dos (en el que está España y Países Bajos); el grupo tres los forman los siete países que ingresaron en abril de 2013; y los seis países que se unieron en abril de 2014 conforman el grupo cuatro (OGP 2015b).

determinada. "The study found significant and consistent discrepancies in the treatment of individuals according to which group the belonged to. Indeed, institutions often seemed more sensitive to the identity of the requester than to the content of the request» Open Society Justice Initiative: Transparency \& Silence. New York, 2006 (pág. 161). 
Para incorporarse a la OGP, el primer paso es demostrar un nivel mínimo de compromiso relacionado con los principios de un gobierno abierto en cuatro áreas claves: transparencia fiscal, acceso a la información, declaraciones patrimoniales de funcionarios públicos electos y de alto rango, y participación ciudadana. Para esto, un país elegible [candidato] debe obtener al menos el $75 \%$ de los puntos disponibles en su caso. Sobre la importancia del acceso a la información pública, se otorgan cuatro puntos a los países que cuenten con leyes de acceso a la información y tres puntos si un país tiene una disposición constitucional que garantice el acceso a la información.

Si un país cumple con los criterios de elegibilidad, el segundo paso dado por el gobierno es indicar su interés de participar en la Alianza mediante una carta de intención a los presidentes y copresidentes de la OGP con copia a la Unidad de Apoyo. La carta, que puede provenir de cualquier dependencia gubernamental si cuenta con la aprobación del Jefe de Estado para unirse a la iniciativa, expresa formalmente la intención del gobierno de incorporase a la OGP y el compromiso de respetar los principios de gobierno abierto articulados en la Declaración de Gobierno Abierto. Esta carta de intenciones se publica en el sitio web de la OGP.

El tercer paso es identificar a un ministerio o dependencia que lidere el proceso y comenzar el desarrollo de su plan de acción de gobierno abierto. Al inicio de este proceso la OGP alienta a los gobiernos a establecer un mecanismo formal para facilitar un diálogo permanente con la sociedad civil y garantizar oportunidades para recibir insumos del público. Recomiendan además «programar una llamada con un representante de la Unidad de Apoyo para poder responder a sus preguntas y conectarles con expertos y recursos relevantes» (OGP op. cit. 2015a).

Una vez el gobierno presente su carta de intención, se requerirá al país concluir y publicar su primer plan de acción OGP para el 31 de marzo del año siguiente. La OGP recomienda que en dichos planes de acción se cuente con la participación activa de ciudadanos y sociedad civil.

El Mecanismo Independiente de Evaluación de la OGP (en adelante, IRM) ofrece informes semestrales para cada país participante en la OGP que evalúan a los países participantes en el desarrollo e implementación de sus planes de acción y ofrece recomendaciones técnicas para mejorar los planes de acción futuros.

España envió su carta de interés en participar en la alianza en agosto de 2011 cuando gobernaba el Partido Socialista Obrero Español y presentó su plan de acción en 2012, con el nuevo gobierno del Partido Popular. En dicho plan de acción reconocía que «todas nuestras acciones políticas deben girar en torno a la transparencia y rendición de cuentas, y que la austeridad y eficiencia sean las piedras angulares de una buena gestión» (OGP 2012a, 1). Como detalle muy relevante, reconocían que «en línea con ese espíritu, el gobierno ha estado trabajando en varias medidas, por ejemplo la remisión al 
Congreso del Proyecto de la Ley de Transparencia, Acceso a los Documentos Públicos y Buen Gobierno».

Dicho plan de acción fue posteriormente evaluado por el IRM, que califica a los países participantes en el desarrollo e implementación de sus planes de acción y ofrece recomendaciones técnicas para mejorar los planes de acción futuros. En dicha evaluación, se recoge que el gobierno español preparó el primer plan de acción «sin realizar un proceso de consulta pública y, al hacerlo, no cumplió las recomendaciones de la OGP» (OGP 2012b, 10). El Ministerio de la Presidencia se justificó en la falta de tiempo debido a la celebración de elecciones a finales de noviembre de 2011 y la rápida formación del gobierno.

Respecto a los compromisos, la OGP destaca que España completó cinco del total de los trece redactados en el plan (Ibíd., 11-15): La aprobación de ley orgánica de estabilidad presupuestaria y sostenibilidad financiera en 2012, que regula la publicación en el BOE de las cuentas y auditorías de las entidades públicas; la publicación de los datos estadísticos de criminalidad, que dicen «cubre un vacío demandado por la ciudadanía»; el sistema RED, un servicio de la Tesorería General de la Seguridad Social a empresas y profesionales cuya misión es permitir el intercambio de información y documentos a través de internet; la simplificación de proyectos de evaluación medioambiental, mediante la aprobación del proyecto de ley en 2013 aunque sin «una correcta participación pública en su elaboración»; y la agilización del procedimiento de creación de nuevas empresas, mediante la aprobación de la ley 14/2013 para la regulación de las funciones del Centro de Información y Red de Creación de Empresas.

En cuanto a la relevancia con los compromisos del gobierno abierto, de modo algo negativo, «cinco de los trece compromisos parecen carecer de relevancia con los compromisos del gobierno abierto». Estos son: la citada ley orgánica de Estabilidad Presupuestaria y Sostenibilidad financiera de 2012, pues «su publicación se hace en formato PDF dificultando así su análisis, y no hay un sitio web en específico en donde consultar estas cuentas anuales»; la e-justicia, que no se creará por restricciones presupuestarias, y en cuyo lugar se iniciará el Comité Técnico Estatal de la Administración de Justicia Electrónica a fin de dar pasos hacia la interoperabilidad, sin quedar claro "cómo el compromiso implica los valores del gobierno abierto»; la revisión y simplificación normativa, compromiso que no se ha iniciado, y aunque positivo, «no está claro cómo puede tener relevancia como medio para mejorar la transparencia y/o desarrollar el gobierno abierto»; el citado sistema RED, que de nuevo «no tiene clara relevancia para desarrollar el gobierno abierto»; y la también citada agilización de la creación de nuevas empresas, que no tiene clara relevancia para desarrollar el gobierno abierto ante lo que el IRM propone compromisos como «abrir la información del Registro Mercantil Español», entre otros (Ibíd., 14-15). 
En cuanto a los criterios estrella -el compromiso es claramente relevante con los valores de la OGP, tiene un impacto potencial significativo y ha sido sustancialmente o completamente implementado- cuatro del total cumplen con estos. El primero y más importante de estos compromisos es la aprobación de la Ley de Transparencia, que para la OGP «supera un retraso histórico» (Ibíd., 13), aunque su proceso de aprobación tuvo muchas carencias como la rapidez, falta de transparencia y formatos de consulta débiles. Denuncian que a pesar de que recibió 3.863 aportaciones de los ciudadanos, éstas no se hicieron públicas y sólo algunas fueron incluidas. Tampoco esperaron a la opinión del comité de los treinta y ocho expertos designados por el Centro de Estudios Políticos y Constitucionales para hacer público el anteproyecto, en mayo de 2012. Los ligeros cambios fueron considerados por la OSCE o Access Info como menores o simples cosméticos (Ibíd., 27).

Por su parte, el gobierno de los Países Bajos envió su carta de interés en septiembre de 2011 y presentó su primer plan de acción en abril de 2012, siendo el definitivo de octubre de 2013. En él, Holanda hace toda una declaración de intenciones al resaltar que «nosotros no empezamos desde cero» (OGP 2013a, 5) y para justificarlo, explica iniciativas de gobierno abierto llevadas a cabo por el Ministerio de Infraestructuras y Medio Ambiente, por ejemplo: la consulta a los ciudadanos sobre las áreas de descanso, a fin de valorar éstas y crear datos abiertos relacionados; la ley de permisos medioambientales con implicación de los ciudadanos en la redacción de la misma; o el proyecto de la región de Tilburg sobre valoración de la propiedad. Este proyecto de transparencia reside en una web especializada que informa a los residentes sobre cómo se valora su propiedad y les permite comparar la información, a fin de darles una mejor visión de su propiedad, calcular sus impuestos locales y corregir información imprecisa. En su caso, como ya poseía una ley de acceso a la información, la conocida como WOB (1991), que veremos más adelante, se adquieren una serie de compromisos como «poner la información del gobierno accesible activamente» (OGP 2013a, 16) en formatos que sean compatibles con los estándares de aperturismo, a fin de retirar obstáculos técnicos y de otra índole, para su reutilización y maximizar su valor social. En segundo lugar, propone medidas de gobierno colaborativo, en donde los ciudadanos son invitados a trabajar activamente en soluciones para asuntos sociales y, por último, medidas de gobierno accesible que toman una aproximación proactiva para dar información sobre servicios y cambios en el ambiente físico que impacten directamente en los ciudadanos. En este caso se enseña a los ciudadanos qué datos se usan en qué procesos y se les la oportunidad de corregirlos cuando sea necesario.

El Informe del IRM destaca respecto a estos compromisos que Holanda completa sólo dos de los dieciocho redactados en el plan de acción (OGP 2013b, 3): la web Volgdewet.nl, por medio de la cual garantizan mayor transparencia en la 
toma de decisiones y los ciudadanos hacen cumplir la ley, pero que, aseguran, «no puede usarse en su plena capacidad hasta que el calendario legislativo sea accesible públicamente»; y el compromiso «De las leyes a la libertad» (Ibíd., 9), basado en treinta nuevas legislaciones y que resultó en algunas innovaciones menores pero con poco impacto en las prácticas administrativas.

En cuanto a la relevancia con los compromisos del gobierno abierto, de modo positivo, sólo dos de los dieciocho parecen carecer de relevancia con dichos compromisos. Esto son: la coalición del agua, que busca optimizar el sistema de aguas mediante empresas privadas y compromisos con la sociedad civil, del que los evaluadores del IRM no entienden qué impacto ha tenido en el gobierno abierto; y los servicios públicos y la perspectiva del usuario, cuyo objetivo es mejorar la calidad de la interacción del sector público con los ciudadanos en relación con servicios integrados y online, pero que de nuevo «no está claramente conectado con los valores centrales del gobierno abierto» (Ibíd., 9-10).

En referencia a los mencionados criterios estrella, cumple cuatro de los dieciocho: apertura de presupuesto y gastos, publicado por el ministerio de Finanzas en formato abierto desde 2012 (y que la OGP considera debe exigirse al resto de organismos del Gobierno); modernización del calendario legislativo, necesario para la apertura legal y cuya revisión está prevista para 2014; cambio de actitudes y procedimientos, con herramientas para fomentar el gobierno abierto; y notificaciones y anuncios online, permitiendo que la publicación online de la legislación sea el primer formato.

Aunque los objetivos planteados para España y Holanda son diferentes y sus informes de avance abarcan a su vez periodos diferentes, 2012-2013 para España y 2013-2014 para Holanda, es interesante realizar la comparativa de ambos estados. En resumen, parece que España sale a rasgos generales mejor parada, puesto que cumple cinco de sus trece compromisos (38\% en términos relativos), frente a dos de los dieciocho que cumple Holanda (11\%). En cuanto a los criterios estrella reúne cuatro sobre trece (un $31 \%$ ) respecto a los cuatro sobre dieciocho de Holanda (un $22 \%$ ). La única excepción es en cuanto a la relevancia de los compromisos de gobierno abierto, en el caso de España son cinco sobre trece (38\%) los que no son relevantes frente a dos de dieciocho (11\%) en Holanda.

\section{HISTORIA. EL INTENTO DE CREAR UN DERECHO FUNDAMENTAL}

Pese que el citado Convenio de Tromsø no haya entrado en vigor, sí que constituye un referente de primer orden para estudiar los marcos legislativos español y holandés de acuerdo a los requisitos establecidos en el convenio. La OGP, por su parte, orienta a los estados comprometidos hacia un sistema 
de democracia más avanzado y con mayor participación de los ciudadanos. Desde sendos marcos, a continuación vamos a realizar un análisis comparativo paso a paso de ambos escenarios español y holandés.

\subsection{España. Fuera de los derechos fundamentales}

Un importante sector de la doctrina propugna el reconocimiento del derecho de acceso a la información pública como un derecho fundamental anclado en la libertad de información del artículo 20 de la Constitución española. Esta reivindicación se plasma en el primer principio de la Coalición Pro Acceso (2016). Sin embargo, dicho reconocimiento no se ha logrado ni en la Ley 19/2013 de Transparencia, ni hasta el momento en la jurisprudencia española.

La importancia de la libertad de información en una sociedad democrática es una referencia recurrente en la jurisprudencia del Tribunal Constitucional español. El párrafo primero del artículo 20 de la Constitución reconoce las libertades informativas que precisan de una interpretación a partir de la Declaración Universal de Derechos Humanos y los tratados internacionales sobre derechos humanos ratificados por España. Además del artículo 19 de la Declaración Universal de Derechos Humanos (1948), deberíamos citar el artículo 19 del Pacto Internacional de Derechos Civiles y Político (1966) y el artículo 10 del Convenio Europeo para la Protección de los Derechos Humanos y las Libertades Fundamentales (1950) como normas esenciales para interpretar el artículo 20.

El artículo 20.1 d) de la Constitución española en su primera frase reconoce el derecho «a comunicar o recibir libremente información veraz por cualquier medio de difusión». Esta provisión es muy parecida al artículo 10 del citado Convenio Europeo de Derechos Humanos, que ampara «la libertad de opinión y la de recibir o de comunicar informaciones o ideas sin que pueda haber injerencia de autoridades públicas y sin consideración de fronteras». Desde un importante sector doctrinal se defiende que la facultad de recibir información integrada en la libertad de información, da pie al reconocimiento a acceder a la información pública como un derecho fundamental. En definitiva, el derecho de acceso a la información pública estaría anclado en el artículo 20 de la Constitución. A nivel internacional el Tribunal Europeo de Derechos Humanos de Estrasburgo ha interpretado desde el año 2009 que el derecho de acceso a la información pública se encuentra amparado en el citado artículo 10 del Convenio europeo, esto es, que se encuentra «anclado» a la libertad de información ${ }^{4}$.

${ }^{4}$ Pueden citarse los casos Társaság a Szabadságjogokért v. Hungary, 14 abril 2009 (Aranzadi JUR/2009/168003); Kenedi v. Hungary, 26 mayo 2009 (Aranzadi 
La Ley 19/2013, de 9 de diciembre, de transparencia, acceso a la información pública y buen gobierno, vincula el derecho de acceso a la información pública al artículo 105.b de la Constitución española (puede verse la evolución del proyecto de ley hasta que se convierte en ley en la obra de Emilio Guichot (2014)). Este precepto regula el «acceso de los ciudadanos a los archivos y registros administrativos, salvo en lo que afecte a la seguridad y defensa del Estado, la averiguación de los delitos y la intimidad de las personas». El precepto no está en el Título Primero de la Constitución dedicado a los derechos y deberes fundamentales sino en el Título dedicado al Gobierno y la Administración, carece por tanto de la protección de los derechos fundamentales y es insuficiente para exigir la transparencia en otras instituciones fuera del poder ejecutivo.

Lo cierto es que la palabra «transparencia» u otra similar como principio de funcionamiento de la Administración Pública no aparece en la Constitución Española de 1978 y, cualquier reforma de nuestra carta magna debería introducirla. En cambio sí aparecen en ocho artículos y con diferentes significados las palabras «acceso» y «acceder».

Repasando la evolución del derecho de acceso a la información en manos de las autoridades públicas, ésta ha sufrido una importante evolución en España. Desde el principio administrativo del secreto como forma de actuación eficaz, pasando por el derecho a obtener información propia con objeto de poder defenderse ante la administración, la facultad a acceder a nuestros propios datos personales o el insatisfactorio desarrollo del artículo 105. b) de la Constitución, en la Ley 30/1992, de 26 de noviembre, de Régimen Jurídico de las Administraciones Públicas y del Procedimiento Administrativo Común (en adelante LRJ-PAC). En dicha Ley el artículo 38 establecía: «Los ciudadanos tienen derecho a acceder a los registros y a los documentos que, formando parte de un expediente, obren en los archivos administrativos, cualquiera que sea la forma de expresión, gráfica, sonora o en imagen o el tipo de soporte material en que figuren, siempre que tales expedientes correspondan a procedimientos terminados en la fecha de la solicitud».

En el propio Preámbulo de la Ley 19/2013, de 9 de diciembre, de transparencia, acceso a la información pública y buen gobierno (op. cit.) se refiere a que la LRJ-PAC «adolece de una serie de deficiencias que han sido puestas de manifiesto de forma reiterada al no ser claro el objeto del derecho de acceso, al estar limitado a documentos contenidos en procedimientos administrativos ya terminados y al resultar su ejercicio extraordinariamente limitado en su articulación práctica». En coherencia con lo anterior, la propia ley modifica la LRJPAC y asume la regulación de la transparencia en el poder ejecutivo.

JUR/2009/218749) y Youth Initiative for Human Rights v. Serbia», 25 de junio de 2013. 


\subsection{Países Bajos. Principio de Gobierno Abierto desde 1983 pero fuera de los derechos fundamentales}

La transparencia es una preocupación de largo recorrido en los Países Bajos. En 1795, la Declaración de los Derechos del Hombre de los Países Bajos recogía, de modo muy similar a Francia:

«Todo el mundo tiene el derecho a exigir de cada funcionario de la administración pública, la rendición de cuentas y justificación de su conducta» (Banisar 2006, 18).

En el siglo XX, la Constitución de los Países Bajos recoge el derecho de acceso a la información pública, aunque no lo hace en su primera edición de 1972, sino que lo incorpora como un principio de actuación pública en 1983 mediante su artículo 110: «En el ejercicio de sus deberes, los órganos del Gobierno deberán observar el derecho de acceso público a la información de conformidad con las normas que sean prescritas por ley en el Parlamento» (Constitution 1983).

Aunque este artículo ha sido reconocido de forma general como una obligación por los órganos del Gobierno hacia el aperturismo y la publicación de la información, no se considera que provea a los ciudadanos del derecho a solicitar el acceso sino que es más bien visto «como un principio general de gobierno abierto» (Leenknegt 2002, 341). Tampoco recoge el texto constitucional holandés la palabra transparencia, tal y como reclaman los expertos españoles, pero sí que aparecen varias referencias a la publicidad de las actuaciones públicas como el artículo 66, «las sesiones del parlamento se llevarán a cabo en público»; el primer párrafo del 80 , «las recomendaciones formuladas por los órganos mencionados en el presente capítulo se hará públicas según lo establecido por ley del Parlamento»; el 121, «excepto en los casos establecidos por ley, los juicios se celebrarán a puerta abierta y las sentencias deberán especificar las bases en las que se apoyan. Las sentencias deben ser pronunciados en público»; el primer párrafo del 125, «las provincias y municipios estarán dirigidas por consejos provinciales y municipales, respectivamente, sus reuniones serán públicas salvo casos establecidos por ley del parlamento»; el segundo párrafo del 133, «el poder legislativo y otros poderes de los órganos administrativos de los consejos de agua y el acceso público a sus reuniones se regirán por la ley del parlamento» y el segundo párrafo del 134, «las funciones y organización de los organismos públicos, la composición y poderes de sus órganos administrativos y el acceso público a sus reuniones se regirá por ley del Parlamento. Se podrán conceder poderes legislativos a sus órganos administrativos de conformidad a la ley del Parlamento».

Como se aprecia, todos estos artículos de la Constitución de los Países Bajos se refieren al acceso público a reuniones de los órganos consultivos, 
órganos de representación y del Poder Judicial entre otros, pero ninguno establece un derecho concreto de acceso a la información.

Junto a esto, parece que, al igual que en el caso español, dicha regulación queda fuera de los denominados «derechos fundamentales» (englobados del artículo uno al veintitrés), pues no es recogida hasta el artículo 110. A este respecto, el mencionado profesor G. Leenknegt (op. cit., 344), de derecho público de la Universidad de Tilburg, considera que el concepto de derecho de acceso a la información es de tal «madurez constitucional» que debe ser incluido en el capítulo uno, referido a los derechos fundamentales de la Constitución.

Como consecuencia de dichas demandas, ha habido varios debates para reformar la Constitución e incluir el derecho de acceso a la información entre los derechos fundamentales.

El informe de la Comisión Franken, encargado por el Gobierno y redactado en 2000 por el Comité de los Derechos Fundamentales en la era digital, redactó cinco recomendaciones para mejorar el acceso a la información pública así como la mejora de acceso a documentos en la era de las nuevas tecnologías (Ibíd., 328). Una de sus pretensiones era reformar la Constitución de los Países Bajos para añadir el derecho fundamental de acceso a la información pública ya que, como se explicaba anteriormente, ésta recoge la obligación de los órganos del Gobierno hacia el aperturismo y la publicación de la información, pero no considera que provea a los ciudadanos del derecho a exigir el acceso.

El primer resultado pudo verse en octubre de 2000, cuando el Gobierno propuso un nuevo derecho fundamental referido al derecho de acceso a la información de las autoridades públicas: «Todo el mundo tendrá derecho de acceso a la información en poder de las autoridades públicas. Este derecho puede ser limitado por o según una ley del Parlamento. Debe ser una preocupación de las autoridades asegurar el acceso a la información en poder de las autoridades» (Tweede Kamer 2000, 30). Sin embargo, esto no desembocó en una reforma de la Constitución, anunciada de nuevo en 2002, pero no culminada.

Respecto a la modificación de la WOB, siguiendo el repaso de la profesora Groothuis (op. cit., 69), el primer paso tuvo lugar en 2004 con la publicación de un informe de investigación sobre el funcionamiento de la Ley de Gobierno Abierto. El segundo paso fue una carta de mayo de 2011 del entonces ministro Donner a la Cámara Baja y la posterior consulta pública online sobre el anteproyecto de la Ley de Enmienda de la WOB.

El tercer paso fueron los proyectos de ley de gobierno abierto propuestos por Peters y Voortman, del partido GroenLinks; y Schouw, del D66. Así, la historia revela amagos de avance, que no se han traducido en modificaciones reales de la Constitución y sólo parciales de la WOB. 


\section{DOCTRINA SOBRE TRANSPARENCIA}

\subsection{España. Un exceso de normas}

La existencia de una ley de transparencia es, según muchos autores, un potente indicador para medir la transparencia de un Gobierno. Hollyer, Rosendorff y Raymond $(2011,1194)$ lo consideran una de las principales fuentes de transparencia, junto con la que llaman «oportunidad» de provisión de datos por el gobierno, según la velocidad con la que los datos aparecen en el Indicador de Desarrollo Mundial y las estadísticas financieras internacionales del Fondo Monetario Internacional. El otro indicador es la posesión de una prensa libre de propiedad privada.

En el proceso de elaboración de la Ley de Transparencia, 2011 se constituye como «el año del impulso definitivo» con una «cronología vertiginosa» (Guichot op. cit., 21) que culmina en la aprobación de la ley a finales de 2013 con una complicada entrada en vigor. Hasta su aprobación, España era «el único país de Europa con más de un millón de habitantes que aún no tiene una norma de estas características» (Tu derecho 2012) y sólo existía un insatisfactorio desarrollo del citado artículo 105 b) de la Constitución en la LRJPAC y normas sectoriales como la Ley $37 / 2007$, de 16 de noviembre, sobre reutilización de la información del sector público, la Ley 38/2003, de 17 de noviembre, General de Subvenciones, la Ley 11/2007, de 22 de junio, de acceso electrónico de los ciudadanos a los Servicios Públicos... o la Ley 27/2006, de 18 de julio, por la que se regulan los derechos de acceso a la información, de participación pública y de acceso a la justicia en materia de medio ambiente ${ }^{5}$, explicada más adelante. Tampoco poseía España una agencia o comisionado específico al que reclamar las denegaciones y contestaciones a las solicitudes de los ciudadanos sobre información pública. Mientras, países como Finlandia o Suecia contaban con una ley de transparencia desde 1766, Francia tenía la Ley de Acceso a Documentos Públicos desde 1978, el mismo año en que se aprobaba la Constitución Española y Gran Bretaña, la Freedom Of Information Act desde 2000.

En 2013, la aprobación de la ansiada ley de transparencia vino a dejar un nuevo sabor agridulce, ya apuntado desde la tramitación del anteproyecto en 2012. La ley recurría a la práctica de la LRJ-PAC: la vinculación del derecho de acceso a la información pública al artículo 105 b) de la CE y el olvido del mayoritario reconocimiento de la doctrina en el ámbito internacional como un derecho fundamental. Así, se alude en el preámbulo que «partiendo de la previsión contenida en el artículo $105 \mathrm{~b}$ de nuestro texto constitucional, la

${ }^{5}$ Que vino a sustituir a la Ley 38/1995, de 12 de diciembre, sobre el derecho de acceso a la información en materia de medio ambiente. 
Ley 30/1992, de 26 de noviembre (...) desarrolla en su artículo 37 el derecho de los ciudadanos a acceder a los registros y documentos que se encuentren en los archivos administrativos». Resulta curioso que la ley haga crítica de las deficiencias de la LRJ-PAC, como su falta de claridad y limitaciones, pero después mantenga su vinculación constitucional al artículo $105 \mathrm{~b}$ de la C.E.

Esta vinculación es incorrecta pues dicho artículo se encuentra fuera de los derechos fundamentales, en el Título IV de la CE referido al Gobierno y de la Administración, cuando los sujetos obligados por la ley de transparencia exceden del Gobierno y la Administración, por ejemplo: las entidades locales, las entidades de Derecho Público o el Congreso de los Diputados y el Senado.

Consideramos que el acceso a los archivos y registros es conceptualmente diferente del acceso a la información pública. Por eso, en la ley «falta una referencia explícita y clara a que se trata de un derecho fundamental que es posible y deseable- anclar en el artículo 20 de la CE» (Sánchez de Diego 2012: 1). El propio informe del Consejo de Estado sobre el Anteproyecto de Ley de Transparencia recomendaba «mencionarse expresamente en la exposición de motivos» el artículo 20 de la Constitución (Dictamen, 2012: apartado III), cosa que no se hizo.

Esta desvinculación de la Ley de Transparencia del artículo 20.1 en favor del 105 da lugar a otra problemática, como es la existencia en la actualidad de diez leyes autonómicas y una estatal, además de varias normas sectoriales sobre las que no existe ningún tipo de coordinación desde la Ley de Transparencia. Al estar el artículo 105 ubicado fuera de los derechos fundamentales de la Constitución Española, la Ley de Transparencia no puede ser de carácter orgánico y, por tanto se limita a un carácter administrativo que puede ser regulado por las Comunidades Autónomas.

En este sentido es preciso recoger las palabras del doctor Miguel Ángel (Blanes 2015, 31): «en prácticamente un año, hemos pasado de no tener en España una ley específica en materia de transparencia a tener once hasta el momento. Sin duda, este aluvión de normas oscurecerá en buena parte la indispensable transparencia».

Según explica Blanes, tras un análisis del diario de sesiones del Congreso de los diputados de fecha de 30 de mayo de 2013, comprobó desolado que algunos partidos políticos (se intuye que mayoritariamente los nacionalistas) «se negaron a que el derecho de acceso a la información pública fuera reconocido como un derecho fundamental porque ello implicaría su regulación por ley orgánica y la exclusión de las competencias autonómicas en la materia y, por ende, la imposibilidad de aprobar una ley de transparencia propia» (Ibíd., 33-34). Esta posición es considerada como «la más plausible» por el coautor de este artículo (Sánchez de Diego 2013, 302), pues «si se trata de 
una mera cuestión de transparencia administrativa, entonces las autonomías sí que tienen competencia, y esa es la máxima preocupación de algunos nacionalistas: el ámbito competencial».

En general, la desvinculación de la ley del artículo 20 de la Constitución parece sólo ser origen de problemas y desventajas. Por ello en una futura reforma de la Constitución, debería introducirse el principio de transparencia en la regulación de los poderes públicos, $\mathrm{y}$ un derecho fundamental a acceder a la información pública dentro de las libertades públicas informativas.

\subsection{El escenario holandés. Una sola norma}

En los Países Bajos, el derecho de acceso a la información fue aprobado en 1980 y especificado definitivamente en 1991 por medio de la WOB. Ésta se desarrolla en conexión con el mencionado artículo 110 de la Constitución, a fin de revisar la legislación concerniente al aperturismo y el acceso público a la información gubernamental e incorporarlos a la legislación de los Países Bajos.

En este escenario, observamos cómo de nuevo se repite la problemática española vinculando la ley a un artículo que se encuentra en la Constitución holandesa fuera de los calificados como derechos fundamentales. En este sentido, los expertos como Groothuis recomiendan la reforma de la Constitución, primero (explicada previamente) y de la legislación, después.

Pese a esta deficiente situación, sí es destacable que, a diferencia de España, sólo existe una ley estatal de gobierno abierto y acceso a documentos públicos. Así, por medio de ésta puede realizarse peticiones a todos los miembros del poder ejecutivo estatal, regional y local, según exige el convenio de Tromsø.

\section{INFORMACIÓN PROACTIVA Y REUTILIZACIÓN}

\subsection{España. Esfuerzo del Portal de Transparencia con reutilización deficiente}

En 2012 se produce un significativo esfuerzo hacia la apertura y reutilización de datos públicos, pues a principios de año el Ministerio de Hacienda y Administraciones Públicas pone en marcha el portal de Gobierno Abierto: datos.gob.es, que analiza y gestiona el catálogo de información pública de la Administración General del Estado. Sin embargo, en 2013, los datos eran aún escasos y obtenerlos del portal era sumamente oneroso.

En ese año, la Ley de Transparencia contrae una obligación de publicidad activa o proactiva en sus artículos cinco y diez. Ésta se entiende como el acceso facilitado directamente por la administración a los ciudadanos sin que 
medie una petición; en oposición a la publicidad reactiva, facilitada por las administraciones tras una petición de acceso (Access Info 2010).

Publicidad activa, sí, pero ¿dónde?, se pregunta Burgar $(2016,19-20)$, pues «parece que el legislador haya dejado a la libre elección de los sujetos sometidos a las diferentes obligaciones de publicidad activa la determinación del lugar (electrónico) en el que llevar a cabo el cumplimiento de sus obligaciones proactivas de transparencia, ya sea, indistintamente, en su página web o en su sede electrónica (...) o en el Portal de la Transparencia»,

Burgar resuelve mediante una interpretación integradora de las previsiones contenidas en la ley de transparencia, en relación, con la Ley 40/2015 de Régimen Jurídico del Sector Público: «el establecimiento de una sede electrónica conlleva la responsabilidad del titular respecto de la integridad, veracidad y actualización de la información y los servicios a los que puede accederse a través de la misma» (Ibíd., 22).

Así, el Portal de Transparencia habrá de configurarse con las características técnicas y jurídicas propias de una sede electrónica, constituyendo, en sí mismo, una auténtica sede electrónica o, por mejor decir, una sede electrónica derivada o subsede» (Ibíd., 23).

Por su parte, la Ley 37/2007, de 16 de noviembre, sobre reutilización de la información del sector público, se refiere en su artículo 5.2 a los documentos que las Administraciones Públicas «procurarán, siempre que ello sea posible y apropiado, proporcionarlos en formato abierto y legible por máquina». Así, la Ley de Transparencia adquiere en el artículo 5.4 el compromiso de emplear «preferiblemente, formatos reutilizables», lo cual implica, como mínimo, formatos como xls y csv, con los que puede trabajarse posteriormente en una hoja de cálculo. El proceso de acceso también es gratuito y está exento de cualquier coste.

Hablar de reutilización nos lleva a citar la Directiva 2013/37/UE del Parlamento Europeo y del Consejo, de 26 de junio de 2013, por la que se modifica la Directiva 2003/98/CE relativa a la reutilización de la información del sector público. Esta última define en su artículo 2 la reutilización como «el uso de documentos que obran en poder de organismos del sector público por personas físicas o jurídicas con fines comerciales o no comerciales distintos del propósito inicial que tenían esos documentos en la misión de servicio público para la que se produjeron». El intercambio de documentos entre organismos del sector público en el marco de sus actividades de servicio público no se considerará reutilización».

En la nueva directiva se establecen definiciones acordes con los nuevos tiempos y las nuevas formas de periodismo como el periodismo de datos, que trabaja con bases de datos en formatos abiertos y reutilizables.

Entre las definiciones incorporadas en 2013 está la de «formato legible por máquina»: un formato de archivo estructurado que permita a las 
aplicaciones informáticas identificar, reconocer y extraer con facilidad datos específicos, incluidas las declaraciones fácticas, los metadatos y su estructura interna. También, la de «formato abierto»: un formato de archivo independiente de plataformas y puesto a disposición del público sin restricciones que impidan la reutilización de los documentos. Por último, se incorpora la «norma formal abierta»: una norma establecida por escrito que especifica los criterios de interoperabilidad de la aplicación informática.

Fuera de la optimista legislación, la realidad no lo es tanto. Aunque se cumple con el punto cuarto, y la información se publica en el portal de transparencia de forma medianamente clara, estructurada y entendible, con interfaces sencillas en forma de símbolo o dibujo, a medida que se avanza en el acceso al documento, la presentación se va complicando.

Junto a esto, se aprecian carencias e información no reutilizable pues del total de documentos contenidos en la web, sólo un par pueden obtenerse en formato csv. Todo esto se desarrolla en un artículo de la coautora de este artículo (Tejedor 2015), unos días después de cuya publicación se da una nueva imagen a la web.

\subsection{Holanda. La reutilización se cobra}

El artículo ocho de la WOB habla de información publicada «espontáneamente». Esto se entiende como información publicada voluntariamente o, en línea con la definición anteriormente expuesta, proactivamente. Esta información es la referida «a su política y la preparación y ejecución de la misma, cuando la provisión de dicha información vaya en el interés de una gobernabilidad democrática efectiva».

Junto a esto, deberá garantizar que la información se proporcione de una manera comprensible y que satisfaga tanto a la parte interesada como al mayor número de miembros del público posible y en un periodo de tiempo adecuado que les permita dar a conocer sus visiones a la autoridad administrativa.

Además, el artículo 9 en sus primeros apartados fija que las recomendaciones de los comités de seguimiento independientes de las autoridades administrativas «deben ser puestas a disposición pública cuando sea necesario y, si es posible, con notas explicativas». También, que el periodo «no será superior a cuatro semanas tras haber sido recibidas por la autoridad administrativa».

Esta información puede hacerse disponible incluyéndose en una publicación comercial, de forma separada pero a disposición pública o para inspección para copia o préstamo.

En lo referido a la reutilización, en 2005, a raíz de la aprobación de la citada directiva del consejo sobre reutilización de la información del sector 
público, se añade un nuevo capítulo $\mathrm{V}$ para recoger el derecho de toda persona a solicitar al gobierno o autoridad pública la reutilización de información, indicando únicamente la información que se desea reutilizar, sin necesidad de acreditar algún interés, aunque con la posibilidad de exigir por el organismo una mayor especificación de la petición, cuando ésta haya sido formulada de forma muy general (WOB op. cit., art. 11b). Estas condiciones cumplen con los requisitos establecidos por la Coalición Pro Acceso, pues no exigen indicar motivos ni aportar datos personales.

Además, en este mismo artículo se recoge que, en la medida de lo posible, los documentos estén disponibles para su reutilización electrónica, lo que parece implicar el empleo de formatos reutilizables, aunque estos no se mencionen expresamente. Sin embargo, se incluye que «no se garantizará el derecho exclusivo a la reutilización a menos que sea necesario para la provisión de un servicio de interés general», y en tal caso se revisará tres veces al año si continúa existiendo tal interés general.

En general, la regulación de la reutilización en la ley resulta anacrónica y adolece de una reforma para incorporar las nuevas medidas y acepciones recogidas en la directiva europea de 2013 sobre reutilización, como la incorporación de formato legible por máquina y formato abierto.

Pero sin duda el punto más negativo es la introducción en el artículo $11 \mathrm{~h}$ de costes de obtención de la información reutilizada, que «no deberán superar los de recopilación, producción, reproducción y diseminación de la información así como el de rendimiento justo de la inversión realizada», aunque se podrán crear reglas más estrictas según orden del Consejo. Esto supondría en la práctica la imposición de costes para casi todas las peticiones, puesto que muchas solicitudes de documentos tienen por fin su reutilización con fines distintos del propósito inicial.

\section{SUJETOS OBLIGADOS}

\subsection{España. Amplio ámbito de aplicación pero en desiguales niveles}

El artículo segundo de la Ley de Transparencia se establece un amplísimo ámbito subjetivo de aplicación, con diversos niveles de sujeción (Blanes $o p$. cit, 34). Pese a lo desordenado del artículo, en la tramitación parlamentaria se incorporaron más sujetos obligados que los contemplados inicialmente en el proyecto de Ley.

En el nivel alto se encuentran la Administración General del Estado formada por los órganos centrales y los organismos vinculados o dependientes como las entidades gestoras y los servicios comunes de la Seguridad Social, las mutuas de accidentes de trabajo y enfermedades profesionales 
colaboradoras de la Seguridad Social, los organismos autónomos, las Agencias Estatales, las entidades públicas empresariales y las entidades de Derecho Público, así como las universidades, además de las Administraciones de las Comunidades Autónomas y de las ciudades de Ceuta y Melilla, también se encuentran en este nivel las entidades que integran la Administración Local.

En el nivel medio se ubican las corporaciones de Derecho público, como los colegios profesionales o cámaras de comercio, además de la Casa de su Majestad el Rey, el Congreso de los Diputados, el Senado, el Tribunal Constitucional y el Consejo General del Poder Judicial, el Banco de España, el Consejo de Estado, el Defensor del Pueblo, el Tribunal de Cuentas, el Consejo Económico y Social y las instituciones autonómicas análogas. Estas entidades sólo están obligadas por la ley en relación con sus actividades sujetas a Derecho Administrativo, tal referencia nos lleva al absurdo jurídico de que la transparencia afecta a sus funcionarios, pero no al personal laboral (Sánchez de Diego 2013, 305). Para mayor complicación, estos organismos son directamente retirados del ámbito subjetivo de aplicación del Real Decreto por el que se aprueba el reglamento de desarrollo de la ley 19/2013 (Real Decreto 2015, art. 1.2), que está aún en periodo de aprobación.

En el nivel bajo, se encuentran los partidos políticos, las organizaciones sindicales y empresariales y las entidades privadas que perciban durante el periodo de un año ayudas o subvenciones públicas en una cuantía superior a 100.000 euros o cuando al menos el $40 \%$ del total de sus ingresos anuales tengan carácter de ayuda o subvención públicas, siempre que alcancen como mínimo la cantidad de 5.000 euros. Estos organismos sólo están obligados por la publicidad activa del capítulo segundo de la ley en lo referido a la publicidad de sus contratos, convenios, subvenciones y ayudas públicas. No están obligados a responder directamente a las solicitudes de información de los ciudadanos, que pueden realizar su consulta al ente público que proporciona fondos públicos, por lo que el acceso a la información se realiza de forma mediada.

Además, el artículo 10 recorta a posteriori este ámbito de aplicación en lo referido a la publicidad activa en el portal de transparencia, que sólo contendrá «la información de la Administración General del Estado cuyo acceso se solicite con mayor frecuencia», lo cual resulta contradictorio.

\subsection{Holanda. Sólo el poder ejecutivo}

La WOB se aplica a los ministerios, a los gobiernos de las provincias, municipalidades, organizaciones industriales y de aguas, así como a todos los gobiernos bajo su responsabilidad de los cuerpos mencionados. 
Así, queda englobado el poder ejecutivo, desglosado en el gobierno central y el autonómico y el municipal; pero deja fuera al Parlamento ${ }^{6}$, a los tribunales y jueces y a las compañías privadas.

Esta omisión del parlamento, que no cumple con lo establecido por el convenio de Tromsø, no responde a un motivo claro, y si Holanda firma dicho convenio internacional deberá adecuar su legislación nacional.

Tampoco existe un código específico que regule la ética y la conducta esperada de los miembros del Parlamento y concretamente de los representantes de la Tweede Kamer. Sin embargo, la Constitución de los Países Bajos, en su enmienda de 1983, artículo 60, requiere a aquéllos que acepten ser miembros del Parlamento «hacer un juramento o afirmación y promesa ante la Cámara según lo prescrito por Ley del Parlamento de que no han hecho nada que pueda excluirles legalmente de ocupar cargos» y «jurar o prometer lealtad a la Constitución y que desempeñarán fielmente sus ocupaciones».

En 2013, un estudio realizado por el Grupo de Estados Contra la Corrupción, grupo evaluador de la prevención de la corrupción entre los miembros del parlamento, jueces y fiscales, llegó a la conclusión de que: «la razón principal para la ausencia de un código uniforme de conducta/ética en el Parlamento Holandés es que las autoridades públicas han sido reticentes a mezclarse en lo que veían como los asuntos internos de los partidos políticos, que tradicionalmente han tenido valores y principios morales diferentes» (GRECO 2013, 11).

Así, si bien considera que los miembros del Parlamento deben tener su propia moralidad, deposita la labor de control a éstos en otros organismos como los partidos políticos. Estos son los responsables de seleccionar a los miembros del Parlamento, ubicarlos en una lista de candidatos a las elecciones y hasta obligarles a ceder su puesto en caso necesario, aunque esto puede suponer una quiebra del mandato representativo. Por otro lado los medios de comunicación juegan un importante rol como perro guardián, al sacar a la luz cualquier conducta no ética de un miembro del Parlamento.

Junto a esto, en el estudio se resalta cómo son los propios miembros del Parlamento los que han rechazado adoptar un código uniforme de conducta/ ética. Entre las razones dadas por éstos a los responsables del estudio: el nivel de integridad entre los miembros del Parlamento es alto y éstos cuidan su comportamiento ante la vigilancia de los medios de comunicación, no hay un concepto común entre los parlamentarios de lo que es ético y lo que no lo es. Este argumento para el grupo evaluador contradice el del alto nivel de integridad de

${ }^{6}$ El Parlamento neerlandés (Staten Generaal) se divide en dos cámaras: la Cámara Baja (Tweede Kamer der Staten-Generaal) y la Cámara Alta (Eerste Kamer Der StatenGeneraal). 
los parlamentarios o la idea que los miembros del Parlamento sólo deben rendir cuentas ante el público por su conducta, por medio de elecciones (Ibíd., 11).

Sin embargo, los miembros del grupo evaluador no se muestran convencidos de estos argumentos ya que, en primer lugar, son conscientes de la existencia de malas conductas entre los miembros del Parlamento. En general, consideran que el Parlamento debe tratar las cuestiones de integridad por sí mismo y no delegar en otras instituciones como los partidos políticos, que pueden tener la tentación de ocultar o encubrir malas conductas para prevenir daños a la reputación del partido.

Como conclusión, el informe del GRECO recomienda que se incorporen en la WOB o se desarrollen códigos de conducta para los miembros de ambas cámaras del Parlamento, y sean adoptados con la participación de sus miembros y puestos fácilmente accesibles al público.

\section{SOLICITUD DE ACCESO Y TRAMITACIÓN}

\subsection{España. Complicado proceso informático con un mes de respuesta}

La Ley de Transparencia establece que la solicitud se puede presentar por cualquier medio que permita tener constancia de: la identidad del solicitante; la información que se solicita; una dirección de contacto, preferentemente electrónica; y la modalidad que se prefiera para acceder a la información.

En la práctica, el derecho a la solicitud de información solo puede ser ejercido a través del Portal de Transparencia si se cuenta con un DNI electrónico, un certificado digital o si se aporta un número de teléfono o un número de cuenta para darse de alta en el sistema Clave. Esto hace que Victoria Anderica, ex coordinadora de campañas de Access Info Europe, la considere «sin ninguna duda la ley más restrictiva del mundo en cuanto a los requisitos para solicitar información y va en contra del Convenio del Consejo de Europa sobre Acceso a Documentos Oficiales» (Access Info 2014). La propia presidenta del Consejo de Transparencia y Buen Gobierno reconoció que la exigencia de identificación disuadía al ciudadano medio de realizar una petición, y estaba en la base del reducido número de peticiones realizadas en su primer año de vida, sólo 2.862. La presidenta el Consejo de Transparencia y Buen Gobierno promete vencer estas dificultades y asegura que hablará con los responsables del portal para que faciliten el acceso siguiendo incluso el ejemplo del Portal de Aragón, donde se pueden realizar las peticiones oralmente (Arizmendi 2015, 61).

La parte positiva es que finalmente el solicitante «no está obligado a motivar su solicitud de acceso a la información», según el artículo 17.3. Recoge, de este modo, el principio cuarto de la Coalición Pro Acceso (op. cit. 2016), pues consideran que incluir los motivos no concuerda con los estándares internacionales y disuade de pedir información. 
Por su parte, la posibilidad de la petición por los solicitantes en cualquiera de las lenguas cooficiales del Estado supone una mejora formal pero no afecta al aspecto sustantivo de transparencia.

En cuanto a la tramitación, cuando la solicitud no identifique de forma suficiente la información, junto a la llamada al solicitante para que concrete la información, se le informará «de la suspensión del plazo para dictar resolución» (op. cit.: art. 19.2).

Una vez realizada la solicitud el acceso posterior a la información vuelve a ralentizarse, pues el portal da de respuesta un «plazo máximo de un mes desde la recepción de la solicitud por el órgano competente para resolver» (Ibíd.: art.20), no desde la realización de la solicitud. Así, si una solicitud se realiza el 1 de enero, pero el órgano competente para resolverla no la recibe hasta el 1 de febrero, el plazo máximo de respuesta sería el 1 de marzo, lo que legalmente entra dentro del mes de plazo de contestación, pero supone una demora real de dos meses.

En la respuesta, de nuevo nos encontramos con problemas, pues en España sigue existiendo el silencio administrativo negativo, en principio como excepcional, ya que el artículo 43.1 de la LRJ-PAC establece como habitual ante la falta de contestación de la Administración Pública que se presuma que contesta afirmativamente, lo que se denomina silencio administrativo positivo. Sin embargo, según el artículo 20 de la Ley de Transparencia si no se contesta una solicitud de información, se considera que se ha respondido negativamente pues «transcurrido el plazo máximo para resolver sin que se haya dictado y notificado resolución expresa se entenderá que la solicitud ha sido desestimada». Tanto la Ley de Transparencia de Navarra como las propuestas de los expertos en transparencia, por ejemplo de la Coalición Pro Acceso, se decantan a favor del silencio administrativo positivo, para evitar la inacción de los entes públicos.

Aún se comprende menos que en el acceso a la información pública se establezca una excepcionalidad sobre el procedimiento administrativo común. En éste cuando se recurre en alzada un silencio administrativo negativo y se produce otro silencio administrativo, entonces se genera un silencio administrativo positivo que entiende estimada la solicitud. Sin embargo, en el acceso a la información pública denegada por silencio administrativo y reclamado ante el Consejo de Transparencia y Buen Gobierno, la falta de resolución expresa en el plazo de tres meses, da lugar a otro silencio administrativo negativo.

\subsection{Holanda. Proceso por correo postal con un matiz que hace la diferencia}

La WOB recoge en su segundo artículo que «toda autoridad administrativa debe, en el ejercicio de sus funciones, revelar información de acuerdo 
con la presente Ley, sin prejuicio de las disposiciones establecidas en otros estatutos».

Así, permite en su artículo tres que toda persona pueda solicitar información sobre cuestiones administrativas a las oficinas del Poder Ejecutivo o alguno de los organismos o instituciones que desarrollen labores por las que sean responsables ante aquél. En esa misma sección se recoge la obligación de especificar el asunto o el documento sobre el que el solicitante requiere la información. Esto implica indicar en detalle los nombres y apellidos de los altos cargos sobre los que se requiere la información. A su vez, el peticionario no debe alegar un interés en su petición pero si su cuestión es demasiado general debe especificarla lo más pronto posible.

La petición se puede hacer de forma oral o escrita, por correo postal o correo electrónico, aunque no hay una aplicación informática al respecto y el peticionario debe dirigirse a la dirección de consultas genérica del ministerio correspondiente.

En cuanto a la forma de acceso a la información, la Administración puede suministrar los documentos requeridos de diversas formas: «emitiendo una copia de los documentos o transmitiendo su contenido exacto de alguna otra forma, permitiendo al solicitante tomar nota de los contenidos de los documentos, suministrando un extracto de los documentos o un sumario de sus contenidos o suministrando la información contenida en los documentos» (Ibíd.: art. 7.1).

Para la elección de uno de estos métodos, la Administración deberá tener en cuenta la preferencia del solicitante y la rapidez del proceso, lo cual da prevalencia a las necesidades de acceso de dicho solicitante.

En cuanto a la tramitación, la ley holandesa fija de nuevo largos plazos. A pesar de que se establece que la Administración debe decidir acerca de la solicitud de información lo antes posible, acto seguido se puntualiza que «en ningún caso más de cuatro semanas desde el día siguiente a aquel en que la solicitud fue recibida» (Ibíd.: art. 6.1). Este plazo fue ampliado respecto del establecido por la ley en sus inicios, de dos semanas, lo cual supone un retraso considerable en el plazo de contestación en línea con las legislaciones más lentas (como el caso español) y un distanciamiento de la media europea, de dos semanas. Sin embargo, cabe apuntar una diferencia con la legislación española y es que, aunque parece que en ambas la respuesta es de un mes, en el caso holandés se refiere a cuatro semanas desde el día siguiente al que la petición es recibida, mientras que en España es un mes desde la fecha de recepción por el órgano competente para resolver. Estas seis palabras hacen la diferencia pues generan la demora explicada anteriormente y suponen un oscuro matiz en nuestra legislación.

Del lado negativo, estas cuatro semanas pueden ser extendidas otras cuatro más, siempre que se comunique el motivo por escrito al solicitante, antes 
de que finalice el primer periodo (Ibíd.: art. 6.2). Además y de modo muy contradictorio, el siguiente apartado permite que se pueda suspender el plazo de respuesta desde el día siguiente a aquél en el que el organismo notifique al solicitante que una tercera parte interesada pueda tener reservas en la decisión tomada.

La otra mejora de la WOB es la inexistencia del silencio administrativo, pues se debe dar notificación por escrito «del rechazo a revelar toda o parte de la información que solicitó» (Ibíd.: art. 5.2) ya fuera esta solicitud por escrito o verbalmente.

\section{LIIMITES, CAUSAS DE INADMISIÓN Y PROTECCIÓN DE DATOS}

\subsection{España. Límites confusos}

A los límites previstos en el artículo 105 b) de la Constitución: seguridad y defensa del Estado, averiguación de los delitos e intimidad de las personas, se añaden los límites que se citan en el artículo 14 de la Ley de Transparencia, el límite a la protección de datos del artículo 15, así como las causas de inadmisión a las peticiones de información que se citan en el artículo 18. Un conglomerado de límites con excepciones particulares que configuran un panorama sumamente confuso.

Algunos de los límites pueden parecer extraños, como el secreto profesional, que no figura como límite en el Convenio de Tromsø. Extraña que los poderes públicos tengan en su poder secretos profesionales, cuando precisamente ese tipo de secreto garantiza la protección de la información frente al poder. En todo caso no sería admisible un secreto profesional del poder público. Otros límites como el medio ambiente chocan con el principio de transparencia de la información medio ambiental que figura en el Convenio de Aarhus y en la Ley 27/2006. Esa doble validez del medio ambiente como justificación en el acceso a la información y como límite es difícilmente entendible.

Especial consideración merece el derecho a la protección de datos personales como límite del derecho de acceso a la información pública que el artículo 15 de la Ley de Transparencia viene a determinar según las indicaciones del Informe de la Agencia de Protección de Datos. El resultado es complejo, con diferentes niveles según el tipo de datos personales.

Se prevé un primer nivel cuando se trata de datos especialmente protegidos como «ideología, afiliación sindical, religión y creencias» (LOPD 1995, art. 7.2), en los que solo se contempla el acceso al documento con el «consentimiento expreso y por escrito del afectado»» o que el afectado los hubiera «hecho manifiestamente públicos», lo que equivale a decir que en principio muy pocas veces se podrá disponer de tal consentimiento. 
Dentro de este, un subnivel para los datos especialmente protegidos concernientes a «origen racial, a la salud y a la vida sexual» y a la «comisión de infracciones penales o administrativas que no conllevasen la amonestación pública al infractor» donde se exige el consentimiento expreso, salvo que el acceso a la información estuviera amparada por una norma con rango de Ley.

Un segundo nivel de la ley de transparencia concede el acceso a «los datos meramente identificativos relacionados con la organización, funcionamiento o actividad pública del órgano» ${ }^{7}$, además funciona como un criterio en la ponderación con el test del daño.

Un tercer nivel para el resto de datos personales, en cuyo caso se «concederá el acceso previa ponderación suficientemente razonada del interés público en la divulgación de la información...» (Ley transparencia.., art. 15.3) empleando los criterios de menor daño por el paso del tiempo veinticinco años desde la muerte del titular del derecho o, si no es conocida, cincuenta años desde la fecha de los documentos; la investigación con fines históricos, científicos o estadísticos o; «la mayor garantía de los derechos de los afectados en caso de que los datos contenidos en el documento puedan afectar a su intimidad o a su seguridad, o se refieran a menores de edad».

Además, el artículo 15.4 va a permitir implícitamente el acceso cuando existe una «previa disociación de los datos de carácter personal de modo que se impida la identificación de las personas afectadas», lo cual es lógico, pues en ese caso ya no existirían datos personales. El resultado es similar a lo previsto con el resto de los límites, pues se admite que la información sea entregada mediante una «acceso parcial», pero en este caso «deberá indicarse al solicitante qué parte de la información ha sido omitida» (Ibíd., art. 16).

La complejidad en los límites inducirá a negar el acceso con una interpretación extensiva, pues resultará mucho más sencillo para «evitarse problemas». Sin embargo, la acción de interpretación y aclaración del Consejo de Transparencia, Acceso a la Información Pública y Buen Gobierno viene a poner en sus justos términos los límites. Además, la colaboración con la Agencia Española de Protección de Datos Personales se encuentra prevista en la Disposición adicional quinta.

En general, aunque el derecho de acceso a la información pública no exige manifestar el interés o motivo por el que se solicita, a la hora de ponderar derechos en conflicto se emplea el criterio del interés público ${ }^{8}$, del interés particular superior o del interés investigador para apuntalar el derecho de acceso.

7 Ya en la Ley 30/1992 se establece en el artículo 35 b) el derecho de los ciudadanos a «identificar a las autoridades y al personal al servicio de las Administraciones Públicas bajo cuya responsabilidad se tramiten los procedimientos».

${ }^{8}$ Existe una discrepancia significativa entre el interés público citado en los artículos 14.2, 15.2, 15.3 de la Ley de Transparencia y el artículo 3.2 del Convenio de Tromsø. 


\subsection{Holanda. Positiva valoración del interés público.}

La WOB original fijaba varias excepciones y restricciones al acceso a la información. Así, el artículo 10 recoge que la revelación de la información no será aplicable cuando «pueda poner en peligro la unidad de la corona, dañar la seguridad del Estado o cuando los datos se refieran a compañías y procesos de manufacturación y sean proporcionados al Gobierno confidencialmente por personas físicas o legales».

La revisión posterior de la ley añadió la excepción a la revelación de los datos personales, pero únicamente de los denominados «datos personales especiales», referidos a la religión, filosofía, raza, ideas políticas, salud, vida sexual, afiliación a sindicatos, según lo recogido en la Ley de Protección de Datos Personales o WBP (Ibíd., art.16). Se deja un punto de inflexión, al quedar fuera los casos en que «no se infrinja la privacidad».

Esta provisión deja un margen a la revelación de datos personales no especiales así como aquéllos especiales que no infrinjan la privacidad. Está en línea, aunque con mayor ambigüedad, con las excepciones recogidas por la FOIA estadounidense, que exceptúa el acceso a los datos de carácter personal sólo cuando constituya una invasión injustificada de la privacidad personal.

La ley de acceso a datos neerlandesa establece, además, una provisión muy importante: la información será también omitida cuando el interés de la revelación no "pese más» que una serie de intereses. Así, de nuevo regula de modo similar a la FOIA estadounidense, que para decidir si se produce o no una invasión injustificada en la intimidad, establece una balanza entre el interés de revelación frente al interés de protección.

Los intereses referidos que constituyen los límites son: las relaciones entre los Países Bajos y otros estados u organizaciones internacionales; los intereses económicos y financieros del Estado y otros organismos públicos o administrativos; la investigación de delitos criminales y la persecución de los delincuentes; la inspección, control y vigilancia por las autoridades administrativas; el respeto a la privacidad personal; la importancia de que el destinatario sea el primero en conocer la información; y la prevención de ventajas desproporcionadas o desventajas de las personas físicas o jurídicas afectadas o de terceras partes (Ibíd., art. 10.2).

Además, en el artículo siguiente recoge: «cuando los documentos hayan sido elaborados para consulta interna, las opiniones personales no serán reveladas excepto cuando sea en el interés de la democracia efectiva de gobierno».

La información medioambiental tiene, por su parte, excepciones limitadas, como se explicará más adelante.

La protección de datos se regula por medio de la citada WBP que establece definiciones muy similares a la LOPD española como, por ejemplo: 
«datos de carácter personal», «fichero», «procesamiento de datos» o «controlador/responsable del fichero». Sin embargo, a la hora de hablar de la persona titular de los datos objeto de tratamiento, le denominan «data subject» (Ibíd.: art. $1 \mathrm{f}$ ) al igual que la Directiva Europea sobre Protección en el Tratamiento de Datos Personales (1995), y traducido al español como «titular de los datos». Así, se evita caer en la confusa denominación del artículo 3 de la LOPD al titular de los datos como «afectado o interesado».

Junto a esto, mientras la LOPD española obliga al «consentimiento del interesado» (Ibíd., art.3 h) para el tratamiento de datos personales que le conciernen, de nuevo la WBP habla del consentimiento del «titular de los datos» (op. cit., art. 1 i) para el tratamiento de los datos personales. En general, a lo largo de toda la WBP se habla del titular de los datos, nunca del interesado, lo que implica un uso más inequívoco del lenguaje, ya que queda claro que se refiere a la persona titular de los datos y no al que simplemente esté interesado en el acceso.

Por otro lado y al igual que ocurre con la LOPD, la WBP también exige para el tratamiento de datos personales que el titular de los datos haya dado «inequívocamente» su consentimiento y sólo contempla en su artículo 8 una serie de excepciones a dicho consentimiento, en sintonía con lo establecido en el 7 por la directiva europea como que el tratamiento sea necesario para llevar a cabo un contrato del que el titular de los datos formara parte, para tomar medidas en respuesta a una pregunta suya, para proteger sus intereses vitales, etc.

\section{8. ÓRGANO DE CONTROL}

\subsection{España. Órgano de control dependiente}

El órgano de control planteado inicialmente por la ley de transparencia, la Agencia de Transparencia, pasa a denominarse Consejo de Transparencia y Buen Gobierno (en adelante CTBG). Este tiene «personalidad jurídica propia y plena capacidad de obrar» y se dice que actúa «con autonomía y plena independencia en el cumplimiento de sus fines» (Ley de Transparencia, op. cit.: art. 33.2). Sin embargo, en el artículo 33.1 se descubre que no es plenamente independiente, pues está «adscrito al Ministerio de Hacienda y Administraciones Públicas», lo que implica la sujeción de su personal a ese ministerio.

El CTBG tiene un presidente, en este caso presidenta, Esther Arizmendi, funcionaria del Estado con más de treinta años de experiencia, por lo que se hace gala de la elección del titular «de entre personas de reconocido prestigio y competencia profesional» (Ibíd.: art.37).

Del lado positivo, dicho presidente será nombrado por un periodo no renovable de cinco años, por lo que no coindice con el mandato del Gobierno. 
Sin embargo, lo será «a propuesta del titular del Ministerio de Hacienda y Administraciones Públicas» (art.37.1), lo que «hace que este organismo sea juez y parte a la hora de decidir sobre un conflicto» (Access Info 2014 op. cit.).

Entre sus funciones figuran las de adoptar recomendaciones para el mejor cumplimiento de las resoluciones de la ley y asesorar en materia de transparencia. Pero para Access Info apenas se desarrollan los poderes y las facultades del Presidente del Consejo de Transparencia.

En segundo lugar, el CTBG está compuesto por la Comisión de Transparencia y Buen Gobierno, que a su vez está formada por el Presidente del CTBG, un Diputado, un Senador, un representante del Tribunal de Cuentas, un representante del Defensor del Pueblo, otro de la Agencia Española de Protección de Datos, otro de la Secretaría de Estado de Administraciones Públicas y un último de la Autoridad Independiente de Responsabilidad Fiscal. De nuevo Access Info (op. cit.) destaca «la poca credibilidad con la que nace el Consejo de Transparencia, no solo por su falta de independencia formal en la ley sino porque en la práctica ni siquiera han planteado pluralidad política en la elección de la Comisión». Lo cierto es que la Comisión del CTBG parece estar compuesta por cargos políticos o administrativos.

Es importante destacar que «la condición de miembro de la comisión no exigirá dedicación exclusiva ni dará derecho a remuneración» (Ley transparencia, op. cit.: art. 36.3). Como excepción, el artículo siguiente establece que el Presidente del Consejo de la Transparencia y Buen Gobierno «percibirá las retribuciones fijadas de acuerdo con el Real Decreto 451/2012 ...». Esto supone que sólo el presidente de dicho consejo percibirá retribución económica, lo que consideramos lógico ya que es el cargo con mayor responsabilidad e independencia respecto del resto de los que componen la comisión.

El CTBG pasa a ser el órgano para la interposición de reclamaciones en materia de acceso y será sustitutivo del circuito ordinario de los recursos administrativos. Sin embargo, se excluyen de su competencia los recursos contra las resoluciones dictadas por la Casa Real, el Congreso de los Diputados, el Senado, el Tribunal Constitucional, el Consejo General del Poder Judicial, el Banco de España, el Consejo de Estado, el Defensor del Pueblo, el Tribunal de Cuentas, el Consejo Económico y Social e instituciones análogas, contra los que sólo cabrá la interposición de recurso contencioso-administrativo (Ibíd., art. 23 1. y 23.2.).

En cuanto a las reclamaciones, la disposición adicional cuarta permite que las comunidades autónomas atribuyan la competencia para la resolución a dicho consejo por medio de convenio con la Administración General del Estado. Por el contrario, elimina la obligación del Presidente del Consejo Estatal de Transparencia de elaborar una memoria para el análisis del cumplimiento de las disposiciones. 
En el régimen jurídico se recoge que el CTBG «anualmente elaborará un anteproyecto de presupuesto con la estructura que establezca el Ministerio de Hacienda y Administraciones Públicas para su elevación al Gobierno» (Ibíd., art.39.1a). Este precepto se cumple para 2015 y los presupuestos y su ejecución presupuestaria se recogen en su web (CTBG 2015a). Sin embargo, no parece un sistema presupuestario independiente puesto que rinde cuentas ante el Gobierno, en lugar de hacerlo ante el Parlamento.

El CTBG también cumple con su obligación por EL artículo 6.2 de ley de publicar los planes y programas anuales de objetivos así como su cumplimiento y resultados, y publica estos en su propia página web, de forma intuitiva, comprensible, y en formatos reutilizables como csv o xls (CTBG 2015b).

\subsection{Holanda. Sin órgano de control}

En la WOB no hay un órgano de control claro y Holanda recibe un 0 sobre 2 en los indicadores 55 y 61 del test de evaluación de Global Right to Information Rating en cuanto a la existencia de «un organismo central, como un comisionado de información, o departamento del Gobierno con la responsabilidad global de promover el derecho de acceso a la información» y «con la obligación de presentar un informe consolidado de la legislatura sobre el desarrollo de la ley» (Access Info 2016).

Tal y como recoge Groothuis (op. cit., 99), ya en el diseño de la primera Ley de Gobierno Abierto en 1975 se planteó un artículo sobre un «Consejo de gobierno abierto» como organismo encargado de promover la transparencia y dar información y supervisión sobre la manera en que se aplica el acceso a la legislación de información por parte del gobierno. Sin embargo, este proyecto finalmente no se incluyó en la ley, y en una carta de modificación de 13 de octubre de 1976, el mencionado artículo fue sustituido por una disposición según la cual el Primer Ministro deberá presentar, en los tres años tras la entrada en vigor de la ley y cada cinco años, un informe a los Estados Generales sobre cómo se aplica la ley.

Tres décadas más tarde, el Ministro del Interior y de Relaciones del Reino encargó un estudio a la Universidad de Groningen sobre las comisiones de información en diversos países y las ventajas y desventajas de tal institución. Los investigadores concluyeron en su informe final que «el establecimiento de un comisionado de información sería una forma apropiada para la mejora del clima público en los Países Bajos, la creación de conciencia entre los ciudadanos y gobierno en torno a la apertura y», por supuesto, «la instauración de un cuerpo accesible para la resolución de disputas públicas (Ibíd., 100).

De nuevo, el proyecto de ley de 2014 (Tweede Kamer, 2014) contiene en su artículo siete una propuesta para la creación de un Comisionado de 
Información cuya primera tarea sea promover la aplicación de la ley mediante el suministro de información por los organismos gubernamentales y otros. Junto a esto, educar a las personas encargadas de la aplicación de la ley, supervisar y presentar informes sobre la aplicación, solicitar y dar consejos al gobierno y el Parlamento acerca de la aplicación de la ley, publicar directrices, y promover la publicación activa y la accesibilidad de la información.

Groothuis sugiere que este Comisionado de Información propuesto se denomine «Defensor del Pueblo de la Información» (op. cit., 103), para resaltar la posición de defensor del pueblo adjunto en el área de gobierno abierto.

Así, como se puede apreciar, en el citado contexto de debate sobre la conveniencia de renovar la WOB también se ha planteado la cuestión de si es deseable establecer un Comisionado de Información, aunque este no se ha implementado aún.

\section{EL ACCESO REAL A LOS DATOS}

\subsection{España. Amplias excepciones}

Como caso práctico y significativo podemos referirnos a la solicitud de información en poder del Ministerio de Economía y Competitividad (en adelante MINICO) en relación con los proyectos de investigación sobre comunicación financiados públicamente entre 2007 y 2013 (Sánchez de Diego y Piñuel 2015). Después de una ardua gestión con datos publicados en distintos números del $\mathrm{BOE}$ en formato pdf conseguimos identificar una relación de 201 proyectos, y solicitamos por registro del MINICO (y por tercera vez) los datos de: título, referencia o número del proyecto y convocatoria/fecha, boletín o medio por el cual se ha publicado la resolución, nombre del Investigador/es Principal/es, Universidad y Facultad a la que pertenece/en, teléfono, dirección o email de contacto, memoria científica que se acompañó a la solicitud, cantidad concedida y estado del proyecto de investigación.

Después de haber aportado una relación en Excel de los 201 proyectos obtuvimos una información parcial en la que se nos deniega el teléfono, dirección o email del contacto del investigador principal alegando a la LOPD. Además tampoco se proporcionan las memorias científico-técnicas de los proyectos «por no tener carácter público, ni contarse con la debida autorización de los investigadores principales ni de las instituciones solicitantes de los proyectos pues su suministro podría vulnerar derechos legalmente protegidos en el ámbito de la propiedad industrial o intelectual». Debe tenerse en cuenta, además, la imposibilidad material de suministrar dicha información dada su magnitud: se trata de documentos de una extensión media de treinta páginas para un total de 201 proyectos. No obstante, se 
indica que «en la información suministrada se incluye para cada proyecto un resumen detallado de la memoria científico técnica» (Ibíd.).

Volvimos a solicitar la misma información puntual sobre cinco investigaciones que no habíamos detectado en el BOE, pero de las cuales teníamos conocimiento. Además se solicitó la memoria científica de un proyecto determinado. La respuesta por vía de correo electrónico decía así:

Tabla I

Buenas tardes.

Ha tenido entrada en el registro del Ministerio de Economía y Competitividad una solicitud de datos relativos a diversos proyectos de investigación.

En respuesta a su consulta, le remito a los artículos 14 y 15 de la Ley 19/2013, de 9 de diciembre, de transparencia, acceso a la información pública y buen gobierno, en los que se establecen como límites de acceso: la propiedad intelectual e industrial y por supuesto la protección de datos de carácter personal, motivo por el que no podemos remitirle los documentos de la memoria científico-técnica de los proyectos ni facilitarle los datos personales que solicita.

En aras de la transparencia, todos los datos que pueden publicarse constan en la sede electrónica del Ministerio a la que le remito.

Un saludo.

Departamento Técnico de Humanidades y Ciencias Sociales

*: dthcs@mineco.es

Ministerio de Economía y Competitividad

Dirección General de Investigación Científica y Técnica

Subdirección General de Proyectos de Investigación

P. ${ }^{\circ}$ de la Castellana, 162

28071 Madrid

La contestación se reclamó ante el CTBG y el 25 de enero de 2016 se recibió la contestación en donde se reconocía parcialmente el derecho de acceso. El MINICO remitió el 27 de enero la información requerida, con excepción de aquellos datos solicitados cuya denegación ha sido considerada justificada por el Consejo.

Teniendo en cuenta varias resoluciones localizables en su página web, constatamos que en temas sobre agenda pública se ha resuelto a favor de la petición de información del plan de medios del Instituto de Crédito Oficial. En la resolución, el CTBG consideraba que, «si bien existe un previsible perjuicio económico derivado del acceso a dicha información debido a que 
quedaba limitada la capacidad de negociación de la central de medios con los medios de comunicación, el interés público en conocer el destino final de los fondos públicos destinados a la publicidad institucional era superior» (CTBG 2015c).

\subsection{Holanda. Acceso complicado y no reutilizable}

Para comprobar la aplicación práctica de lo expuesto en la ley, se expone una petición de acceso a datos de declaraciones patrimoniales y de actividades de noviembre de 2013.

Es importante conocer que en los Países Bajos existe una ley general de acceso a la información pública pero no existen leyes secundarias que regulen el acceso a los datos de patrimonio y actividades de los miembros de los poderes públicos. En España, por el contrario, primero se aprobaron leyes sectoriales para la regulación de conflictos de intereses y la publicación del patrimonio y actividades y más tarde se aprobó una ley de transparencia o acceso a datos públicos.

La publicación de las declaraciones de patrimonio y de actividades se realiza en la web oficial del gobierno, pero de modo muy escaso, sin datos concretos de patrimonio y en formatos no reutilizables. En ella, el primer ministro envía al presidente de la cámara de representantes la declaración del patrimonio y actividades.

Como consecuencia, el 14 de noviembre de 2013 realizamos una primera petición por medio de la WOB de las declaraciones patrimoniales de los miembros del Gobierno holandés y ciertos secretarios de Estado pertenecientes al Gabinete al Ministerio del Interior y Relaciones del Reino a fin de obtener dicha información de forma más amplia, recopilada en un solo documento y en formato reutilizable (xls o csv). Esta fue por escrito y se tuvo que especificar la información de modo detallado (según recoge la WOB en su art. 3.2) recogiendo los nombres de todos los ministros y secretarios de Estado que forman el Gabinete. Junto a esto, al no ponerse a disposición del público un formulario online o similar por tuvimos que crear nuestro propio modelo de solicitud.

Dos meses después no se había recibido contestación por lo que el 28 de enero de 2014 reiteramos la petición, incluyendo como destinatario al Ministerio de Asuntos Económicos y reduciendo el número de ministros y secretarios de Estado a la mitad. El 20 de febrero recibimos notificación de ambos ministerios.

En primer lugar, el Ministerio del Interior y Relaciones del Reino, nos comunica que en la primera petición de noviembre de 2013 estaban ausentes los datos de contacto en el impreso, pues sólo figuraban en el remitente del sobre, por lo que la petición no pudo ser procesada. Indica que, una vez 
obtenidos nuestros datos de contacto por medio de la segunda petición, remite la solicitud al Ministerio de Asuntos Generales, el que tiene competencia en la materia. Del mismo modo, el Ministerio de Asuntos Económicos comunica la competencia del Ministerio de Asuntos Generales y la remisión a éste de la solicitud.

En marzo de 2014, recibimos respuesta por parte del Ministerio de Asuntos Generales remitiendo a dos cartas del Gobierno donde se recoge la política de las declaraciones. Remitía también a las declaraciones de los ministros miembros del actual gabinete, recogidas en varias cartas de 2012 a 2014 (Kamerstuk 2014).

Como se puede ver, y aunque no lo dice expresamente, el gobierno holandés no quiso ampliar ni reelaborar la información ni tampoco aportar la misma en un formato reutilizable, sino que remitió la petición a los datos ya recogidos en la web. Además, superó ampliamente el mes de plazo que fija la WOB para resolver.

\section{CONCLUSIONES}

Estableciendo un marco comparativo, destacamos negativamente que ni en la constitución española ni en la holandesa se incluya la palabra transparencia, haciendo caso omiso a los juristas de sendos países que reclaman dicha inclusión. Tampoco aprobamos la inexistencia de un reconocimiento en ambos países del derecho de acceso a la información pública como derecho fundamental de toda persona. Por ello, sería aconsejable una reforma constitucional o un reconocimiento jurisprudencial, apoyado por una ratificación de Tromsø y una modificación de las leyes de transparencia.

En cuanto a la creación de una ley de transparencia, los Países Bajos le llevan la delantera a España, pues veintidós años antes ya contaban con una ley. Sin embargo, esta premura es también su castigo y la ley está hoy desfasada y es bastante inferior a la FOIA inglesa o la estadounidense. Así, ocupa el puesto número 61 sobre 103 países evaluados por el citado ranking (Access Info 2016) frente al puesto 1. ${ }^{\circ}$ de México, el 33 de Reino Unido y el 55 de Estados Unidos.

Entre sus carencias, está ausente de su ámbito de aplicación el poder legislativo y el judicial, no regula un organismo de control independiente, intenta mercantilizar la reutilización y tampoco exige formatos reutilizables en su información proactiva (lo que se hace especialmente patente tras la aprobación en 2013 de la nueva directiva europea sobre la información del sector público). De este modo, y pese a las expectativas iniciales respecto de la norma holandesa, tampoco ésta viene a constituirse como el marco ideal.

Así, corroboramos la visión de Vleugels, cuando asegura que la actual WOB: «aunque moderna en su nacimiento, (su primera versión) fue 
aprobada en mayo de 1980, está seriamente pasada de moda por su limitado ámbito de aplicación, su falta de orientación hacia la demanda de transparencia electrónica y datos abiertos y sus amplias excepciones. Permite prácticas de fácil rechazo de la información, procedimientos muy largos, escasa localización de recursos para realizar peticiones y escasa o irregular revelación proactiva» (Vleugels 2012).

Mientras, España ha hecho de la necesidad, virtud, y el hecho de crear una ley de manera tan tardía le ha permitido solo en parte tomar el ejemplo de aquellas europeas que le han precedido, subsanando los errores de éstas. Al contrario que Holanda, sí incluye parcialmente al poder legislativo, aunque en un nivel medio y referido a sólo actividades sujetas a derecho administrativo, lo cual puede producir muchos conflictos o ser una barrera de opacidad. Lo mismo sucede con el poder judicial, del que incluye únicamente al Consejo General del Poder Judicial. Sin embargo, el desarrollo de la transparencia por parte de dicho Consejo ha de ser evaluado positivamente.

Además, a diferencia de los Países Bajos en donde no existe órgano de control, la ley española crea el CTBG como órgano de control y su actividad hasta el momento puede ser evaluada positivamente, aunque sea dependiente del Ministerio de Hacienda y Administraciones Públicas. También es positivo que en España como principio no se cobre por la reutilización de información pública, aunque la ley de 2007 de reutilización en su artículo 8 prevea que podrá aplicarse una tasa por el suministro de documentos para su reutilización. Junto a esto, en España se promueven moderadamente los formatos reutilizables.

De hecho, España es evaluada más positivamente por la OGP que su vecino del norte, tanto en el cumplimiento de compromisos como en la reunión de criterios estrella, lo cual demuestra un esfuerzo hacia la adaptación al nuevo escenario exigido por esta alianza por el gobierno abierto. No sucede así en el citado ranking de Access Info donde España ostenta un lejano puesto 75 .

Por todo esto, opinamos que la valoración global de la norma española es agridulce pues, aunque viene a completar una insuficiencia manifiesta y ha demostrado un esfuerzo notable, debe remediar todas las citadas carencias para asemejarse a países referencia en transparencia como México.

\section{BIBLIOGRAFÍA}

ACCESS INFO. 2010. «El Derecho de acceso a la información: Definición, protección internacional del derecho y principios básicos». Acceso el 18 de octubre de 2016. $<$ http://www.access-info.org/wp-content/uploads/El_Derecho_de_acceso_a_la_ informacin._principios_bsicos.pdf $>$

- 2014. «La Coalición pro Acceso critica las graves carencias con las que entra en vigor la ley de transparencia». Acceso el 6 de julio de 2016. < http://www. access-info.org/es/esp-es/13630> 
2016. «Global Right To Informacion Rating». Acceso el 18 de octubre de 2016. <http://www.rti-rating.org/country-data/>

Act of 6 July 2000 containing rules for the protection of personal data (Personal Data Protection Act) (Wet bescherming persoonsgegevens) (WBP). Acceso el 4 de julio de 2016. <http://www.freedominfo.org/wp-content/uploads/documents/ NL\%20data\%20protection\%20wettekstwbpuk tcm75-28678.pdf>

ARIZMENDI, Esther. 2015. «Entrevista». Revista Española de la Transparencia, n. ${ }^{\circ} 1$, segundo semestre: 60-69.

BANISAR, David. 2006. «Freedom of Information and Access to Government Record Laws Around The World. A Global Survey of Access to Government Information Laws». Privacy Information n. ${ }^{\circ}$ x: 1-168. Acceso el 18 de octubre de 2016. $<$ http://www.freedominfo.org/documents/global_survey2006.pdf $>$

Blanes, Miguel Ángel. 2015. «¿No querían transparencia? Tomen, 11 leyes». Revista Española de la Transparencia, n. ${ }^{\circ}$ 1, segundo semestre: 31-41.

Burgar Arquimbau, Joaquín Miguel. 2016. «Aspectos formales de la publicidad activa». Revista Española de la Transparencia, n. ${ }^{\circ}$ 2, primer semestre: 19-31.

CoAlición Pro AcCeso. 2016. «Los diez principios». Acceso el 18 de octubre de 2016. <http://www.proacceso.org/>

CONSTITUCiÓn EsPAÑOLA ratificada el 6 de diciembre de 1978. Boletín Oficial del Estado, 29 de diciembre de 1978.

Constitution OF THE KingdOM OF THE NetherLANDS. Netherlands. International Law Review, 30, 1983: 387-410.

Convenio del Consejo de Europa sobre el Acceso a los Documentos Públicos, de 18 de junio de 2009, Council of Europe Treaty Series, n. ${ }^{\circ} 205$. Tromsø. Edición bilingüe en la Organization of American States. Acceso el 20 de octubre de 2016. $<$ http://www.oas.org/es/sla/ddi/docs/acceso_informacion_desarrollos_convenio_consejo_europeo.pdf $>$

Convenio Para la Protección de los Derechos Humanos y de las Libertades Fundamentales. Corte Europea de Derechos Humanos. Roma, 4 de noviembre de 1950. Reforma del 1 de junio de 2010.

COUNCIL OF EUROPE. 2016. "Chart of signatures and ratifications of Treaty 205». Acceso el 18 de octubre de 2016. <http://www.coe.int/en/web/conventions/fulllist/-/conventions/treaty/205/signatures?p_auth=Ji9vl6m4>

CTBG. 2015a. «Presupuestos del Consejo de Transparencia y Buen Gobierno». Acceso el 18 de octubre de 2016. <http://www.consejodetransparencia.es/ct_Home/ $\mathrm{va} /$ consejo/transparencia_buen_gobierno/economia/presupuestos.html>

_. 2015b. «Plan estratégico». Acceso el 18 de octubre. $<$ http://www.consejodetransparencia.es/ct_Home/plan_estrategico.html>

- 2015c. «Reclamaciones». Acceso el 28 de enero de $2016<$ http://www.consejodetransparencia.es/ct_Home/consejo/reclamaciones/novedades/2015/12/2015-12-10-1.html\#.Vpwr1VLGq0k>

Declaración Universal de los Derechos del Hombre. Asamblea General de las Naciones Unidas. 183 a, sesión plenaria. París, 10 de diciembre de 1948.

Dictamen DEL CONSEJO DE Estado 707/2012 sobre el Anteproyecto de Transparencia, Acceso a la Información Pública y Buen Gobierno. Acceso el 21 de octubre de 2016 <http://www.boe.es/buscar/doc.php?id=CE-D-2012-707> 
Directiva 2003/98/CE Del Parlamento Europeo y Del Consejo, de 17 de noviembre de 2003, relativa a la reutilización de la información del sector público. Diario Oficial de la Unión Europea, 31 de diciembre de 2003.

2013/37/UE Del Parlamento Europeo y Del Consejo, de 26 de junio de 2013, por la que se modifica la Directiva 2003/98/CE relativa a la reutilización de la información del sector público. Diario Oficial de la Unión Europea, 27 de junio de 2013 .

- 95/46/CE del Parlamento Europeo y del Consejo de 24 de octubre de 1995 relativa a la protección de las personas físicas en lo que respecta al tratamiento de datos personales y a la libre circulación de estos datos. Diario Oficial de las Comunidades Europeas, 23 de noviembre de 1995.

FERnández Ramos, Severiano y José María PÉREz Monguió. 2014. Transparencia, Acceso a la Información Pública y Buen Gobierno. Pamplona: Thomson ReutersAranzadi.

FoIA. Act to make provision for the disclosure of information held by public authorities or by persons providing services for them and to amend the Data Protection Act 1998 and the Public Records Act 1958; and for connected purposes (Freedom of Information Act). House of Commons, cap. 36, 30 de noviembre de 2000.

GreCO. 2013. «Fourth Evaluation Round». Plenary Meeting. Acceso el 18 de octubre de 2016. <http://www.coe.int/t/dghl/monitoring/greco/evaluations/round4/ Eval\%20IV/GrecoEval4(2012)7_The_Netherlands_EN.pdf $>$

Groothuis, Marga. 2014. «Openbaarheī van overheidsinformatie. Recente rechtsontwikkelingen in Nederland en Europa». Preadviezen 2014 voor de Vereniging voor de vergelijking van het recht van Belgie en Nederland, Boom juridische uitgevers, La Haya: 69-103.

Guichot, Emilio, ed. 2014. Transparencia, Acceso a la Información Pública y Buen Gobierno. Madrid: Tecnos.

Hollyer, James R., B. Peter Rosendorff y James Raymond VReEland. 2011. «Democracy and Transparency». The Journal of Politics, n. ${ }^{\circ}$, Southern Political Science Asociation of Cambridge University: 1191-1205.

INAP. 2016. La normativa autonómica en materia de derecho de acceso a la información pública. Madrid: Colección Estudios y Documentos.

KAMERSTUK. 2014. «Ontslag en benoeming staatssecretaris van Financiënen». Acceso el 17 de octubre de 2016. <https://zoek.officielebekendmakingen.nl/kst33860-2.html>

LEENKNEGT, G. 2002. «The protection of fundamental rights in a digital age». Electronic journal of comparative law, vol 6.4: 326-345.

LEY 27/2006, de 18 de julio, por la que se regulan los Derechos de Acceso a la Información, de Participación Pública y de Acceso a la Justicia en materia de Medio Ambiente (incorpora las Directivas 2003/4/CE y 2003/35/CE). Boletín oficial de Estado, 19 de julio de 2006.

— 30/1992, de 26 de noviembre, de Régimen Jurídico de las Administraciones Públicas y del Procedimiento Administrativo Común (LRJ-PAC). Boletín oficial de Estado, 27 de noviembre de 1992.

37/2007, de 16 de noviembre, sobre Reutilización de la Información del Sector Público. Boletín Oficial del Estado, 17 de noviembre de 2007. 
LeY ORGÁNICA 15/1999, de 13 de diciembre, de protección de datos de carácter personal (LOPD). Boletín oficial de Estado, 14 de diciembre de 1999.

OGP. 2012a. «Spain action plan». Acceso el 4 de julio de 2016. <http://www.opengovpartnership.org/sites/default/files/legacy_files/country_action_plans/OGP\%20 Action\%20Plan\%20SPAIN\%20DEF_2.docx>

. 2012b. «España. Informe de avance». Acceso el 4 de julio de 2016. <http:// www.opengovpartnership.org/sites/default/files/Spain_Final_2012_0.pdf>

- 2013a. «Netherlands, Action Plan Open Government». Acceso el 18 de octubre de 2016. <http://www.opengovpartnership.org/sites/default/files/Netherlands\%20Action\%20Plan\%20Open\%20Government\%20Partnership.pdf $>$

- 2013b. «Netherlands Progress Report». Acceso el 18 de octubre de 2016. $<$ http://www.opengovpartnership.org/sites/default/files/Netherlands_English_ Final.pdf $>$

- 2015a. «Misión y objetivos». Acceso el 4 de julio de 2016. $<$ http://www. opengovpartnership.org/es/acerca-de/misi\%C3\%B3n-y-objetivos>

- 2015b. «Participating countries». Acceso el 4 de julio de 2016. <http:// www.opengovpartnership.org/es/countries>

Pacto internacional De Derechos Civiles y políticos. Resolución de la Asamblea General 2200 A (XXI), de 16 de diciembre de 1966. Nueva York, 19 de diciembre de 1966.

REAL DECRETo XX/2015 por el que se aprueba el reglamento de desarrollo de la ley 19/2013, de 9 de diciembre, de transparencia, acceso a la información pública y buen gobierno, Acceso el 7 de julio de 2016. <http://transparencia.gob.es/transparencia/dam/jcr:328f1e5f-86de-4f59-83f9-fad26b902649/proyecto-reglamento-ley-de-transparencia.pdf $>$

SÁNCHEZ DE DiEGo FERNÁNDEZ DE LA RIVA, Manuel. 2013. «Transparencia y acceso a la información pública ¿son lo mismo? Por un derecho fundamental a acceder a la información pública». En Libertad de expresión e información en Internet. Amenazas y protección de los derechos personales, dirigido por Loreto Corredoira Alonso y Lorenzo Cotino Hueso, 285-323. Madrid: Centro de Estudios Políticos y Constitucionales, n. ${ }^{\mathrm{o}} 225$.

— y José Luis PiÑUel RAIGADA. 2015. «En busca del arca perdida: solicitud de información de proyectos de investigación en comunicación». En Media and Journalists in the Age of Open Government an Transparency, editado por Rodrigo Cetina Presuel y otros, 380-397. Madrid: Cyberlaw

- 2012. «Anteproyecto de Ley de Transparencia, Acceso a la Información Pública y Buen Gobierno». Centro de Estudios Politicos y Constitucionales: 1-4. Acceso el 18 de octubre de 2016. http://www.cepc.gob.es/docs/ley-de-transparencia/cuestiones-juridicas-sz-de-diego.pdf?sfvrsn=0

TEJEDOR FuENTES, Laura. 2015. «Aciertos y fracasos de la ley de transparencia y su portal». Revista Española de la Transparencia, n. ${ }^{\circ}$ 1, segundo semestre: 90-97.

Tu DERECHO A SABER. 2012. «Última oportunidad para una buena ley de transparencia». Blog de Tu Derecho a Saber. Acceso el 4 de julio de 2016. <http://blog.tuderechoasaber.es/tag/coalicion-pro-acceso/>

TWEEDE KAMER. 2000. «Grondrechten in het digitale tijdperken» Acceso el 18 de octubre de 2016. < https://zoek.officielebekendmakingen.nl/kst-27460-1.pdf> 
2014. «Wijziging van de Wet openbaarheid van bestuur in verband met aanvullingen ter voorkoming van misbruiken». Acceso el 4 de Julio de 2016. $<$ https://zoek.officielebekendmakingen.nl/kst-34106-3.html $>$

Vleugels, Roger. 2012. «Dutch Green Party Proposes Revised FOI Law». Freedom Info, 18 de junio. Acceso el 18 de octubre de 2016. <http://www.freedominfo. org/2012/06/dutch-green-party-proposes-revised-foi-law/>

WOB. Wet van 31 oktober 1991, houdende regelen betreffende de openbaarheid van bestuur. Acceso el 13 de enero de 2016. <http://wetten.overheid.nl/ BWBR0005252/geldigheidsdatum_13-01-2016>

TITLE: The right on access to public information in Spain and the Netherlands. Two improbable scenarios.

RESUMEN: Los Países Bajos cuentan con una ley de transparencia desde hace veinticinco años, España sólo desde hace tres. Con motivo del tercer aniversario, este artículo invita a reflexionar acerca de su implantación y las cuestiones a mejorar de ambas legislaciones, como la falta de vinculación a los derechos fundamentales, la ausencia de una mención a la transparencia en sus cartas magnas, los largos plazos de contestación o la ausencia de organismos de control efectivos. Así, desde un estudio comparativo de tipo cualitativo se pretende hacer una aportación constructiva, destacando la mejora en la posición de España según los criterios establecidos por la Alianza por el Gobierno Abierto pero incidiendo en la importancia de seguir progresando.

PALABRAS CLAVE: acceso a datos, acceso a la información, constitución, transparencia, ley de transparencia

ABSTRACT: The Netherlands past its law on access to information twentyfive years ago, Spain only three years ago. The law»s third anniversary is a good moment to think about its implementation and the things to improve of both legislations such as the lack of entailment to fundamental rights, the absence of a mention of transparency in both Constitutions, the long periods to answer and the absence of effective control agencies. Consequently, we pretend to do a constructive contribution from a comparative and qualitative study. Thus highlighting the improvement of Spain»s position according to requirements established by the Open Government Partnership, but remarking the importance of continuing progressing.

KEY WORDS: data access, access to information, constitution, transparency, transparency act

RECIBIDO: 18.03 .2016

ACEPTADO: 19.12 .2016 